Contents list available at IJRED website

Int. Journal of Renewable Energy Development (IJRED)

Journal homepage: www.ijred.com

\title{
Performance of Microbial Fuel Cell for Wastewater Treatment and Electricity Generation
}

\author{
Z. Yavaria ${ }^{*}$, H. Izanloo a, K. Naddafib, H.R. Tashauoeic, and M. Khazaei ${ }^{a}$ \\ a Research Center for Environmental Pollutants and Department of Environmental Health Engineering, \\ Qom University of Medical Sciences, Qom, IRAN \\ ${ }^{b}$ Department of Environmental Health Engineering, School of Public Health and Center for Environmental Research, \\ Tehran University of Medical Sciences, Tehran, IRAN \\ c Department of Environmental Health Engineering, School of Public Health, \\ Islamic Azad University Tehran Medical Branch, Tehran, IRAN
}

\section{Article history:}

Received February 16, 2013 Received in revised form April 14, 2013 Accepted April 28, 2013 Available online

\begin{abstract}
Renewable energy will have an important role as a resource of energy in the future. Microbial fuel cell (MFC) is a promising method to obtain electricity from organic matter and wastewater treatment simultaneously. In a pilot study, use of microbial fuel cell for wastewater treatment and electricity generation investigated. The bacteria of ruminant used as inoculums. Synthetic wastewater used at different organic loading rate. Hydraulic retention time was an effective factor in removal of soluble COD and more than $49 \%$ removed. Optimized HRT to achieve the maximum removal efficiency and sustainable operation could be regarded 1.5 and 2.5 hours. Columbic efficiency (CE) affected by organic loading rate (OLR) and by increasing OLR, CE reduced from $71 \%$ to $8 \%$. Maximum voltage was $700 \mathrm{mV}$. Since the microbial fuel cell reactor considered as an anaerobic process, it may be an appropriate alternative for wastewater treatment
\end{abstract}

Keywords: bacteria, columbic efficiency, electricity, microbial fuel cell

\section{Introduction}

The energy has essential portion in economic, industrial and scientific growth of world. Oil and other fossil fuels, the main energy sources in the world, can provide the energy at least 100 years (Logan, 2007). Fossil fuels combustion release many pollutants such as $\mathrm{CO}_{2}$ to atmosphere which cause to climate changes, global warming, greenhouse effect and so on (Logan, 2007). Use of clean energy like renewable energy will be a suitable alternative to overcome energy crisis and reducing global emissions of $\mathrm{CO}_{2}$ in near future (Logan, 2007; Pant et al. 2010). Microbial fuel cell (MFC) is a new technology for electricity generation and wastewater treatment simultaneously (Rabaey, 2005). In this system microorganisms act as biocatalyst to convert the chemical energy stored in organic compounds directly into electrical energy (Potter, 1991; Liu et al. 2005; Rabaey et al. 2005; Wen et al. 2009; Ahn and Logan, 2010; Pant et al. 2010). MFC has anaerobic and aerobic chambers that separated by membrane (Logan, 2007; Mohan et al. 2008; Ahn and Logan, 2010; Pant et al. 2010). Bacteria in the anaerobic anodic chamber oxidize substrate and release electrons and protons. Electrons move through the wire, while protons permeate through proton exchange membrane to cathode. Then electrons and protons in cathode chamber combine with oxygen molecules to form water (Logan, 2007). Migration of electrons creates potential difference between two chambers that monitored by multitmeter. Although In 1911, Potter, produced electricity from bacteria, but electricity production was less (Potter, 1991). It is well known that various species of bacteria that called exoelectrogens can transfer Electrons of substrates to anode (Logan, 2007; Pant et al. 2010). Previous studies showed that E. coli (Schroder et al. 2003), Shewanella putrefaciens (Kim et al. 2002), Shewanella oneidensis (Biffinger et al. 2008) 
Geobacteraceae sulferreducens (Bond and Lovley, 2003) Rhodoferax ferrireducens (Chaudhuri and Lovley, 2003) would used. Several studies showed that organic compounds such as glucose (Chaudhuri and Lovley, 2003), acetate or butyrate (Liu et al. 2005), domestic wastewater (Ahn and Logan, 2010; Jiang et al. 2009), swine wastewater (Bookie et al. 2005), beer brewery wastewater (Wen et al. 2009), chocolate industry wastewater (Patil et al. 2009) were used as substrate in MFC. In 2004 the research studies showed that there is a directly relationship between electricity production from MFC and wastewater treatment (Logan, 2007). Ahn and Logan (2010) in a study conducted on domestic wastewater treatment with MFC found out that Power density and COD removal were $422 \mathrm{~mW} / \mathrm{m}^{2}$ and $25.8 \%$ respectively. According to Junqiu Jiang, MFC can generate electricity from sewage sludge and Total chemical oxygen demand (TCOD) of the sludge was reduced to $46.4 \%$ (Jiang et al. 2009). Rismani-Yazdi et al (2007), reported the in bio conversation of cellulose into electrical energy in microbial fuel cells, Maximum power density reached $55 \mathrm{~mW} / \mathrm{m}^{2}(1.5 \mathrm{~mA}, 313 \mathrm{mV})$. In a study conducted on capable of converting glucose to electricity at high rate, it was found out power density was $3.6 \mathrm{~W} / \mathrm{m}^{2}$ and Electron recovery occurred to up 89\% (Rabaey et al. 2005).

The purpose of present study was the feasibility of synthetic wastewater treatment and electricity generation with rumen microorganisms as microbial consortium and glucose as the electron donor by MFC. To examine the effect of different organic loading rate on COD removal, Columbic efficiency (CE) and voltage production, MFC operated in continuous mode at during 720 hours.

\section{Material and Methods}

\subsection{MFC reactor and electrodes}

Two-chamber MFC constructed by Plexiglas with internal dimension $10 \times 10 \times 5 \mathrm{~cm}(500 \mathrm{ml})$ and a proton exchange membrane located between anode and cathode chamber (Nafion 117, DuPont Co USA). To increase the porosity of PEM, it was pretreated according to procedure described by Junqiu Jiang (Jiang et al. 2009). PEM prior to use must keep in deionized water .Carbon cloth and graphite flat $(6 \mathrm{~cm} \times 6 \mathrm{~cm})$ without any coating used as electrode in anode and cathode respectively. Both anode and cathode electrodes were positioned in reactor by titanium wires. Before start-up the pilot, the electrodes were pretreated with deionized water during $24 \mathrm{hr}$ (Wen et al. 2005). A schematic of MFC which used in this study is shown in Fig.1.

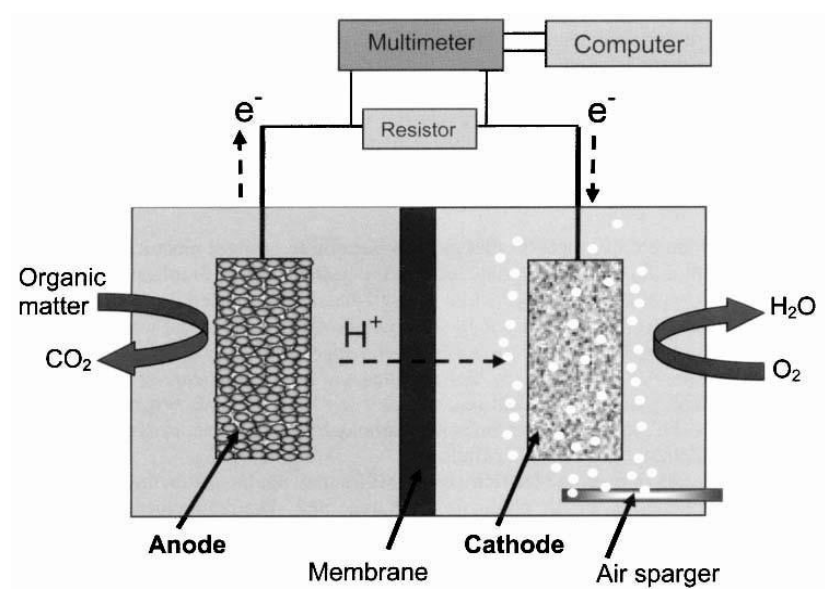

Fig.1 Schematic of microbial fuel cell (Logan 2007)

\subsection{MFC inoculation and operation}

Mixed anaerobic culture acquired from Rumen of cow. Microorganisms in rumen are able to degrade Complex compound and carbohydrates. They grow in anaerobic conditions (Patil et al. 2009).There are about 109 to 1010 bacteria in per $\mathrm{ml}$ of rumen (Mansoori et al. 2007). Synthetic wastewater content of glucose, as carbon source and electron donor, transferred into a flask which sparged with $\mathrm{CO}_{2}$. Glucose is a carbohydrate that microorganisms can degrade easily (Pant et al. 2010). A glucose $(1,2 \mathrm{~g} / \mathrm{l})$ medium, that contained other micronutrients including: $1 \mathrm{~g} / \mathrm{l}, \mathrm{NH}_{4} \mathrm{Cl}, 0.28 \mathrm{~g} / \mathrm{l}, \mathrm{KH}_{2} \mathrm{PO}_{4}$, $0.68 \mathrm{~g} / \mathrm{l}, \quad \mathrm{K}_{2} \mathrm{HPO}_{4}, 0.87 \mathrm{~g} / \mathrm{l}, \quad \mathrm{MgSO}_{4} .7 \mathrm{H}_{2} \mathrm{O}, 0.1 \mathrm{~g} / \mathrm{l}$, $\mathrm{CaCl}_{2} .2 \mathrm{H}_{2} \mathrm{O} \quad 0.1 \mathrm{~g} / \mathrm{l}, \mathrm{NaCl}, 0.58 \mathrm{~g} / \mathrm{l}, \mathrm{KCl}, 0.74 \mathrm{~g} / \mathrm{l}$ and vitamin $1 \mathrm{ml} / \mathrm{l}$ used as anolyte (Wen et al. 2005; Logan, 2007; Patil et al. 2009; Pant et al. 2010). This medium injected to anode chamber by peristaltic pump (Nanozist tech 5760P) at different organic loading rate hydraulic retention time.

Table 1 shows this data. To keep the anaerobic conditions, carbon dioxide $\left(\mathrm{CO}_{2}\right)$ entered to the anode chamber. During operation, the anolyte mixed by magnetic stirring beads (Mohan et al. 2008). In cathode chamber PBS (4.97 g/L NaH $\mathrm{PO}_{4}, 2.75 \mathrm{~g} / \mathrm{L} \mathrm{Na} \mathrm{NPO}_{4}$ ) used as electron acceptor (Pant et al. 2010). Air sparged with pump to provide dissolved oxygen. MFC operated in continuous mode at laboratory temperature 20 $\left( \pm 4^{\circ} \mathrm{C}\right)$.

Table 1

Properties loading of reactor

\begin{tabular}{cccc}
\hline C $[\mathbf{g} / \mathbf{l}]$ & RUN & OLR[kg COD/m $\left.\mathbf{m}^{\mathbf{3}} \cdot \mathbf{d}\right]$ & HRT $[\mathbf{h r}]$ \\
\hline \multirow{2}{*}{1} & 1 & 6.686 & 3.5 \\
& 2 & 9.36 & 2.5 \\
& 3 & 15.6 & 1.5 \\
2 & 4 & 12.274 & 3.5 \\
& 5 & 17.184 & 2.5 \\
& 6 & 28.64 & 1.5 \\
\hline
\end{tabular}




\subsection{Analysis and calculation}

Voltage was measured using a digital multi-meter (RIGOL Digital multimeter DM 3051) continuously. Current (I) calculated Eq.1.

$$
\mathbf{I}=\mathbf{V} \times \mathbf{R}^{-1}
$$

where $\mathrm{V}(\mathrm{V})$ is voltage and $\mathrm{R}(\Omega)$ is resistance (Logan, 2007). Current and power density $\left(\mathrm{mA} / \mathrm{m}^{2}\right),\left(\mathrm{mW} / \mathrm{m}^{2}\right)$ obtained with divide current and power to surface electrode (usually anode) (Liu et al. 2005; Logan, 2007; Pant et al. 2010). Since, power generation is the main purpose in this process, in order to obtain more energy, more electrons that stored in biomass should be extracted (Logan, 2007). Electrons are referred to the columbic efficiency (CE) that calculate using the ratio of electrons obtained from the substrate to the total electrons was stored in substrate. Columbic efficiency in the continuous mode calculated by using $\mathrm{CE}=(8 \times \mathrm{I}) /$ ( $\mathrm{F} \times \mathrm{q} \times \Delta \mathrm{COD}$ ) (Liu et al. 2005; Logan, 2007; Luo et al. 2010; Pant et al. 2010). Where I (A), F Faraday constant (96485C/mol), $\Delta c$ changes COD concentration (mg/l) and $\mathrm{q}$ is flow rate $(\mathrm{l} / \mathrm{d})$ (Logan, 2007). For determination soluble chemical oxygen demand (SCOD) in influent, used Standard Method description (5220; HACH COD system) (APHA, 1998). Samples were filtered through a $0.45 \mu \mathrm{m}$ pore diameter membrane to analyze for SCOD (Liu and Logan, 2004).

\section{Result and Discussion}

When wastewater was pumped in to reactor, multimeter recorded voltage. Maximum voltage was obtained $700 \mathrm{mV}$ after 540 hours in the final OLR. Results of MFC operation during 720 hours is presented in Table 2.

Table 2

Parameters of MFC

\begin{tabular}{ccccc}
\hline RUN & V[mV] & CE [\%] & I [mA/ $\left.\mathbf{m}^{2}\right]$ & E [\%] \\
\hline 1 & 685 & 71.7 & 4.52 & 12.37 \\
2 & 660 & 32.6 & 8.3 & 27.83 \\
3 & 645 & 15.6 & 8.75 & 36.037 \\
4 & 627 & 15.09 & 8.33 & 46.37 \\
5 & 633 & 15.08 & 9.9 & 49 \\
6 & 700 & 8.9 & 9.46 & 40 \\
\hline
\end{tabular}

\subsection{Effect of hydraulic retention time on removal of SCOD}

In order to study the effects of HRT on removal of SCOD, system operated with different concentrations of substrate in three HRTs and six OLRs. To detect the removal efficiency of SCOD, samples were taken from effluent anode chamber. Results showed that the effect of hydraulic retention time on removal efficiency of SCOD is significant. In three primary run, removal efficiency of SCOD increased from $12.37 \%$ to $36 \%$. The optimum retention time observed in HRT $1.5 \mathrm{hr}$. This data is showed in Table 2. Fig. 2 shows removal efficiency of sCOD and HRT in these runs. In later runs that operated with concentration $2 \mathrm{~g} / \mathrm{l}$ of glucose, the maximum removal of SCOD was obtained in HRT $2.5 \mathrm{hr}$. So, the optimized HRT to achieve the maximum removal efficiency and sustainable operation could be regarded 1.5 and 2.5 hours. These results indicate that although the electricity produced in these stages reached to maximum $700 \mathrm{mV}$, but SCOD removal efficiency decreased. In other words, it seems that this range was the optimum retention time to achieve the maximum removal efficiency of COD. This data is showed in Fig. 3. Our results support those of Yujie, study. They showed the optimum hydraulic retention time for maximum power density production and efficiency of COD removal was between 2.5 and 3.5 hours (Feng et al. 2010). Removal efficiency can decrease due to gas production (hydrogen or methane) and other electron acceptor such as diffused oxygen through the membrane (Logan, 2007). The concentration of Substrate in effluent indicated the effectiveness function of specialized microbial species presented in microbial consortium which use the carbon source in synthetic wastewater (Wen et al. 2009).

According to results that illustrate in Table 2, when the organic loading rate increased from 6.68 to $28.64 \mathrm{~kg}$ $\mathrm{COD} / \mathrm{m}^{3} . \mathrm{d}$, columbic efficiency decreased from $71 \%$ to 8\%. Because of Electrons which release from substrate oxidation produced Electricity. For example, complete oxidation of glucose and acetate, produce 24 and 8 mole-/mol, respectively (Chaudhuri and Lovley, 2003; Logan, 2007). Thus in high concentration of substrate more electrons obtained from degradation of substrate and will be ended to increase the current density and reduce the columbic efficiency.

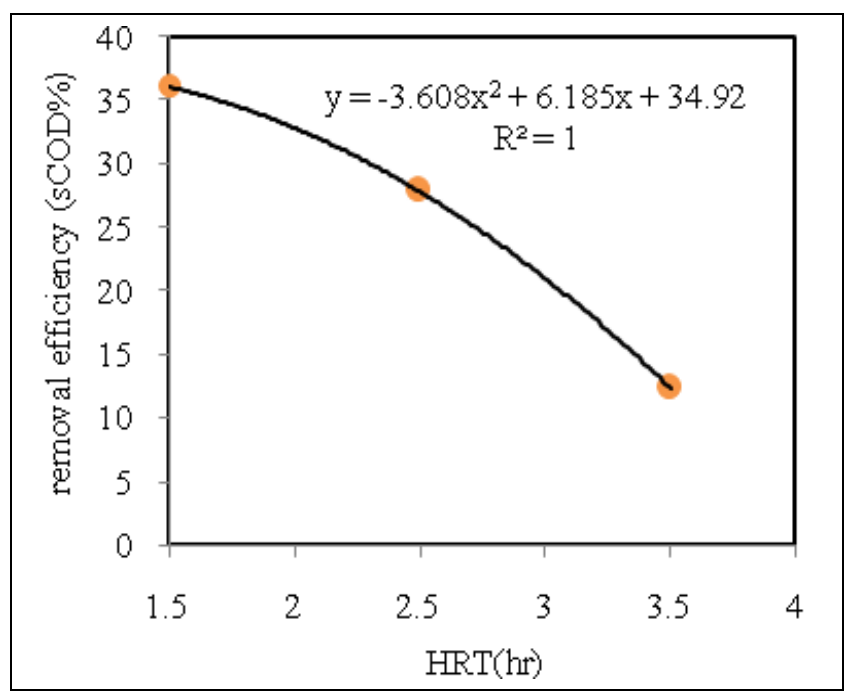

Fig. 2 Removal efficiency of sCOD and HRT for $1 \mathrm{~g} / \mathrm{l}$ substrate 


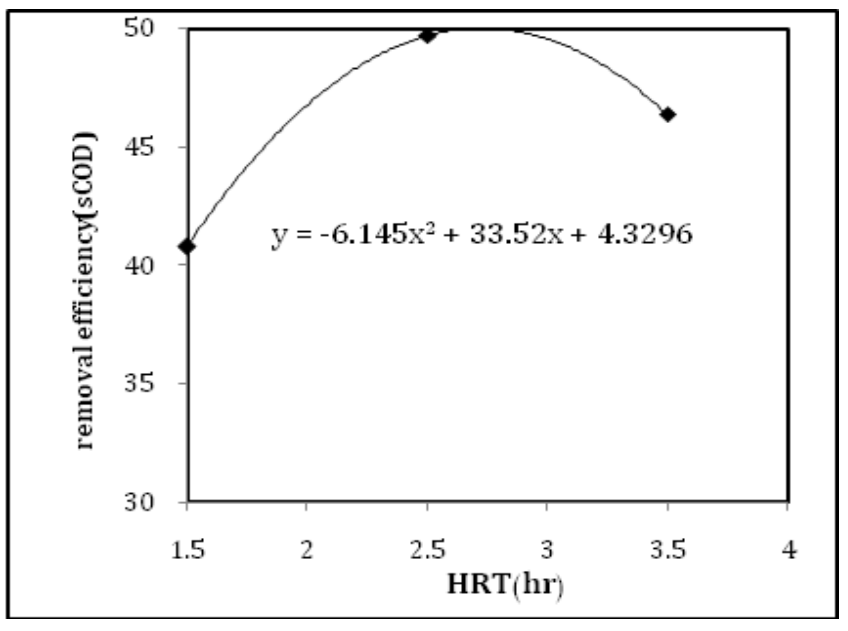

Fig. 3 Removal efficiency of sCOD and HRT for $2 \mathrm{~g} / \mathrm{l}$ of substrate

Fig 3 presents the correlation between $\mathrm{CE}$ and current density is linearly with equation $\mathrm{CE}=1.4507 \mathrm{x}$ (current density) -0.7859 with correlation coefficient of 0.9681. Columbic efficiency for non fermentation substrate (such as acetate and butyrate) is more than fermentation substrate (such as glucose and starch) (Liu et al. 2005; Logan, 2007; Pant et al. 2010). Glucose degrades by fermentation metabolism to ethanol and butyrate. This process cause to electrons cannot produce electricity (Liu et al. 2004; Mansoori et al. 2007). Oxygen diffusion into anode chamber cause to facultative bacteria use the oxygen as terminal electron acceptor and decrease the electrons transfer from circuit and thus current density decrease (Valerie et al. 2011). The results are in agreement with those of Shaon Cheng et al achieved in an air-cathode system using glucose or domestic wastewater as substrates, CE for glucose and wastewater was 60 and $27 \%$ respectively (Cheng et al. 2006). This is possibly due to CE measured the basis of soluble COD.

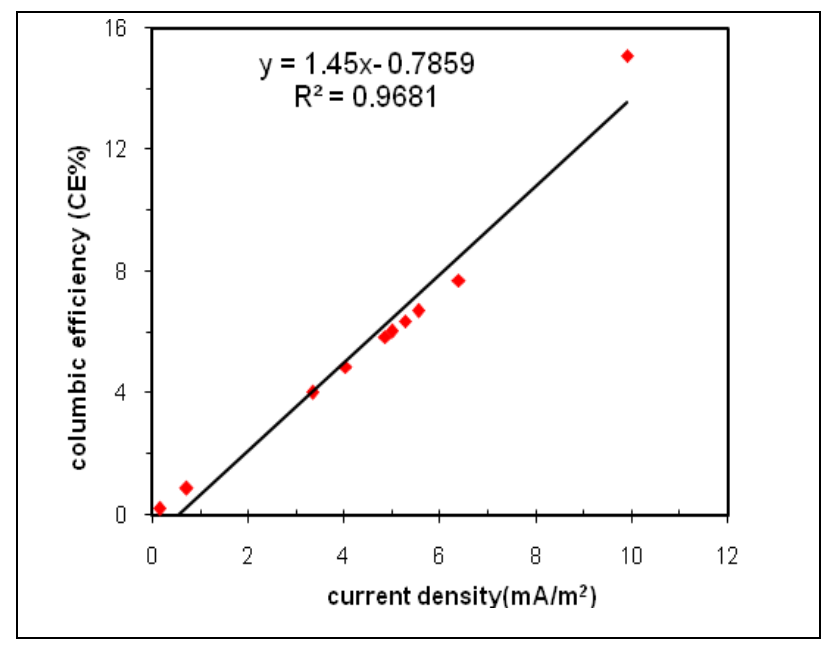

Fig. 4 Columbic efficiency as a linear function of current density
However, the results do not support those of Hong Liu et al ,s study, in that, they found Columbic efficiencies with butyrate were lower than those of acetate (Liu et al. 2005). Rabaey et al (2005) reported in their study on capable of converting glucose to electricity at high rate, the CE was $89 \%$. This is due to the fact that they used hexacyanoferrate for electron acceptor and an enrichment consortium. Q. Wen et.al (2009) showed that may be there are so many reasons for such a low columbic efficiency, such as other electron donors $\left(\mathrm{NO}_{3}^{-}, \mathrm{SO}_{4}^{-2}\right)$, oxygen diffusion to the wastewater, etc.

\section{Conclusion}

The purpose of study was the feasibility of wastewater treatment and electricity generation with rumen microorganisms as microbial consortium and glucose as the electron donor by MFC. According to results of study, maximum voltage in operation was obtained $700 \mathrm{mV}$ after $504 \mathrm{~h}$. At high concentration of substrate the activity of bacteria reduced. This issue may be originated from two reasons. First bacteria used substrate for cell growth and gaining energy. Thus rate of electricity generation decrease. Second substrate consumes by other electron acceptors such as oxygen, nitrate, sulfate and so on that cause to current and CE decreased. In MFCs which glucose is used as substrate, methanogenesis converted it to ethanol, acetate and butyrate. These decomposition processes inhibited electrons from electricity production. At result of CE reduced (Logan 2007). MFC was operated in laboratory temperature $20\left( \pm 4^{\circ} \mathrm{C}\right)$. But researches showed that the thermophilic metabolism has advantages than the mesophilic metabolism. Sarah M. Carver stated the thermophilic condition for wastewater anaerobic digester improved efficiency, and removed many human and animal pathogens (Carvera et al. 2011). It seems operation in thermophilic condition may be useful for improvement of effluent quality. One limitation to this study was that the Fouling of membrane. Black Deposit at side anode and white deposit at side cathode chamber was observed which cause to limit proton transportation. So, suggested in later study use other catholyte and anolyte, and peruse the fouling of membrane. Also operation in continues mode required more energy than batch mode. So, if purpose is electricity generation we recommend further studies using a single-compartment MFC. Because of single-compartment MFC have both simple structure and low internal resistance. These findings has corroborate that the microbial fuel cell reactor is considered an anaerobic process, it has an appropriated alternative for domestic wastewater treatment or pre treatment for industrial wastewater especially wastewater which has high organic loading rate. 


\section{Acknowledgement}

Authors would like to thank the Research Center of Environmental Pollutants, Qom University of medical sciences, for its financial and laboratory assistance.

\section{References}

Ahn, Y. \& Logan, B.E. (2010) Effectiveness of domestic wastewater treatment using microbial fuel cells at ambient and mesophilic temperatures. Bioresource Technology, 101, 469-475.

APHA (1998) Standard Methods for the Examination of Water and Wastewater. American Public Health Association, American Water Works Association, Water Environment Federation, Washington, DC.

Biffinger, J.C., Byrd, J.N., Dudley, B.L. \& Ringeisen, B.R. (2008) Oxygen exposure promotes fuel diversity for Shewanella oneidensis microbial fuel cells. Biosensors and Bioelectronics, 23, 820-826.

Bond, D.R. \& Lovley, D.R. (2003) Electricity production by Geobacter sulfurreducens attached to electrodes. Applied and Environmental Microbiology, 69(3), 1548-1555.

Bookie, M., Jung Rae, Sanguine, K., John, O., Regan, M., Bruce, E. \& Logan, B.E. (2005) Electricity Generation from Swine Wastewater Using Microbial Fuel Cells. Journal of Water Research, 39(20), 4961-4968.

Carvera, S.M., Vuoriranta, P. \& Tuovinen, O.H. (2011) A thermophilic microbial fuel cell design. Journal of Power Resources, 196, $3757-$ 3760 .

Chaudhuri, S.K. \& Lovley, D.R. (2003) Electricity generation by direct oxidation of glucose in mediatorless microbial fuel cells. Nature Biotechnology, 21, 1229-1232.

Cheng, S., Liu, H. \& Logan, B.E. (2006) Increased power generation in a continuous flow MFC with advective flow through the porous anode and reduced electrode spacing. Environmental Science Technology, 40, 2426-2432.

Feng, Y., Lee, H., Wang, X., Liu, Y. \& He, W. (2010) Continuous electricity generation by a graphite granule baffled air-cathode microbial fuel cell. Bioresource Technology, 101, 632-638.

Jiang, J., Zhao, Q., Zhang, J., Zhang. G. \& Lee. D.J. (2009) Electricity generation from bio-treatment of sewage sludge with microbial fuel cell. Bioresource Technology, 100, 5808-5812.

Kim, H.J., Park, H.S., Hyun, M.S., Chang, I.S., Kim, M. and Kim, B.H (2002) A mediator-less microbial fuel cell using a metal reducing bacterium, Shewanella putrefaciens. Enzyme and Microbial Technology, 30(2), 145-152.

Liu, H. \& Logan, B.E. (2004) Electricity generation using an aircathode single chamber microbial fuel cell in the presence and absence of a proton exchange membrane. Environmental Science Technology, 38 4040-4046.
Liu, H., Cheng, S. \& Logan, B.E. (2005) Production of Electricity from Acetate or Butyrate Using a Single-Chamber Microbial Fuel Cell. Environmental Scienence Technology, 39, 658-662.

Liu, H., Cheng, S. \& Logan, B.E. (2005) Production of electricity from acetate or butyrate using a single-chamber microbial fuel cell. Environmental Scienence Technology, 39, 658-662.

Liu, H., Cheng, S. \& Logan, B.E. (2005) Production of electricity from acetate or butyrate using a single-chamber microbial fuel cell. Environmental Science Technology, 39, 658-662.

Logan, B.E. (2007) Microbial fuel cell. $1^{\text {st }}$ ed, John Wiley \& Sons, Publication

Luo, Y., Liu, G., Zhang, R., Zhang, C. (2010) Power generation from furfural using the microbial fuel cell. Journal of Power Sources, $195,190-194$.

Mansoori, H., Nikkhah, A., Rezaeian, M., Mirhadi,A. (2007) Research \& Develop. 66-73

Mohan, S.V., Mohanakrishna, G., Reddy, B.P., Saravanan, R. \& Sarma, P.N. (2008) Bioelectricity generation from chemical wastewater treatment in mediatorless (anode) microbial fuel cell (MFC) using selectively enriched hydrogen producing mixed culture under acidophilic microenvironment Biochemical. Engineering, 39, 121130.

Pant, D., Van, B.G., Diels, L., Vanbroekhoven, K. (2010) A review of the substrates used in microbial fuel cells (MFCs) for sustainable energy production. Bioresource Technology, 101, 1533-43.

Patil, S.A., Surakasi, V.P., Koul, S., Ijmulwar, S., Vivek, A., Shouche, Y.S. \& Kapadnis, B.P. (2009) Electricity generation using chocolate industry wastewater and its treatment in activated sludge based microbial fuel cell and analysis of developed microbial community in the anode chamber. Bioresource Technology, 100(21), 51325139.

Potter, M.C. (1911) Electrical effects accompanying the decomposition of organic compounds, B 84,260-276. Proc. Roy. SOC. London Ser.

Rabaey, K., Boon, N., Hofte, M. \& Verstraete, W. (2005) Microbial phenazine production enhances electron transfer in biofuel cells. Environmental Science and Technology, 39, 3401-3408.

Rabaey, K., Boon, N., Hofte, M. \& Verstraete, W. (2005) Microbial phenazine production enhances electron transfer in biofuel cells. Environmental Science and Technology, 39, 3401-3408.

Rismani-Yazdi, H., Ann D, Christy., Burk A. Dehority., Morrison, M., Zhongtang, Yu., Tuovinen, Olli H. (2007) Electricity generation from cellulose by rumen microorganisms in microbial fuel cells. Biotechnology Bioengineering. 97, 1398-407.

Schroder, U., Nieen, J. \& Scholz, F. (2003) A Generation of microbial fuel cells with current outputs boosted by more than one order of magnitude. Angewandte. Chemie, 42, 2880-2883.

Valerie, J.W., Saito, T., Michael, A.H. \& Logan, B.E. (2011) Polymer coatings as separator layers for microbial fuel cell cathodes. Journal of Power Resources, 196, 3009-3014.

Wen, Q., Wua, Y., Cao, D., Zhao, L. \& Sun, Q. (2009) Electricity generation and modeling of microbial fuel cell from continuous beer brewery wastewater. Bioresource Technology, 100, 41714175 